\title{
FDA regulations restricting the sale and distribution of cigarettes and smokeless tobacco to protect children and adolescents (executive summary)
}

On 10 August 1995, President Bill Clinton announced that the United States Food and Drug Administration (FDA) was proposing rules to restrict the advertising, sale, and distribution of cigarettes and smokeless tobacco to reduce tobacco use among children. The President's announcement, and an FDA press release summarising the proposed rules, were published in Tobacco Control (1995;4:299-309). One year later, on 23 August 1996, President Clinton announced the issuance of final FDA rules.

The regulations ( $p p$ 44615-44618), the FDA's response to the voluminous public comments received ( $p p$ 44395-44614), and the legal basis for the FDA rules ( $p p$ 44619-45318) were published on 28 August as a 924-page tome in the Federal Register (1996;61(168): 44395-44618). These documents can be accessed electronically on the World Wide Web through the FDA's home page $<$ http://www.fda.gov/opacom/campaigns/ tobacco.html> or through the home page of the US Government Printing Office <http:// www.access.gpo.gov/su_docs/fda/index.html/>. Print copies can be ordered for $\$ 62$ per copy (add $25 \%$ for orders outside the United States) from: New Orders, Superintendent of Documents, PO Box 371954, Pittsburgh, Pennsylvania 152507954 USA, tel: +1 2025121800 , fax: +1202512 2250 (request document No 017-012-00377-0).

An executive summary of the rules is published below, in addition to comments by President Clinton in a Rose Garden ceremony at the White House on August 23rd.-ED

\section{Statement by President Bill Clinton}

Thank you very much. Thank you, Linda ${ }^{\star}$, for your courage and your commitment to carry on Victor's legacy and your own crusade. Thank you, Mr Vice President, Secretary [of Health and Human Services (HHS) Donna] Shalala, General [Barry] McCaffrey [Director of the Office of National Drug Control Policy]. I'd like to say a special word of thanks to [Food and Drug Administration] Commissioner [David] Kessler and to Phil Lee, the Assistant Secretary of HHS. In different ways they have a great triumph today. Thank you, Dick Durbin, for being the first member of Congress ever to talk to me about this issue. Thank you, [Congressman] Marty Meehan. Thank you to my former colleagues, the Attorneys General.

*Widow of Victor Crawford, former lobbyist for the tobacco industry, who became a champion for tobacco control as he was dying of smoking-induced lung cancer (see obituary published in Tobacco Control 1996;5:162-3).
Mr [Frank] Kelly [Attorney General of the $\vec{\omega}$ State of Michigan], I know you're retiring this $\stackrel{\Omega}{\rightarrow}$ year as the Senior Attorney General of of America, and we served together back in the $\omega$ dark ages and I can't imagine a more fitting స్ట్ capstone to your career than the fact that you've been a part of this and we thank you. Thank you, [New York City Public Advocate] Mark Green.

I thank all the medical professionals who are here. I thank all the young people who are here, including Anna Santiago and Neal Stewart $\mathbb{\Phi}$ McSpadden, who came out here with us. I $\vec{\theta}$ want to say a special word of thanks to three $\mathscr{\&}$ members of Congress who are not here, but who deserve to be because of their work on this issue-Senator [Frank] Lautenberg of New Jersey, Senator [Paul] Wellstone of Minnesota, and Congressman Henry Waxman of

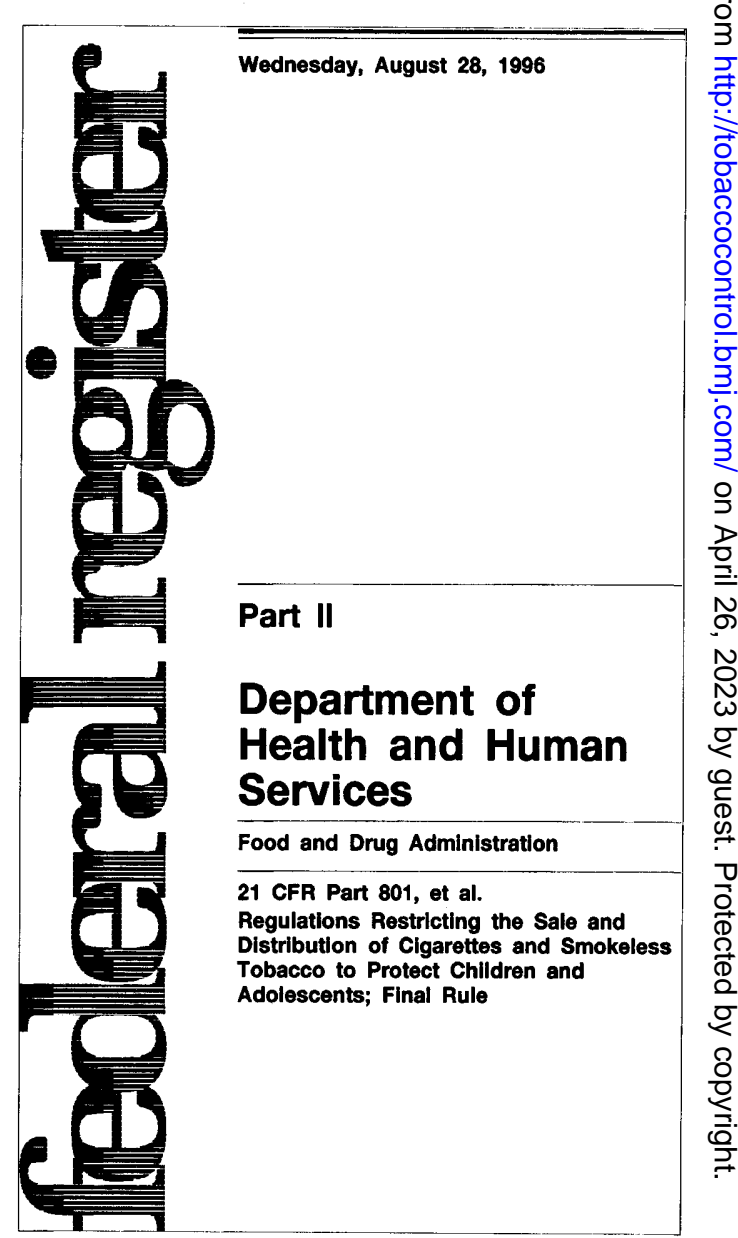

New FDA regulations on tobacco advertising, promotion, and sales. 
California. Thank you, Joe Califano [former Secretary of the Department of Health, Education, and Welfare], for beating on me about these issues all these years we've been friends and long before I ever became President. Thank you, sir. [Laughter.]

Thank you, Dr [C Everett] Koop [former US Surgeon General], for everything you have done to try to bring some sanity into the health policy of this country. This has been a great week for you-we had the KassebaumKennedy bill a couple of days ago and this today. Maybe you can design an encore for us over the next month or two. [Laughter.] But you have been a great force for good in this country and we're grateful to you.

If I might, I'd like to say just a couple of personal words to some people who really deserve an enormous amount of credit for this decision. The Vice President was altogether too modest and too restrained, but the first time we began to discuss this was about the time the FDA opened their inquiry. And he looked at me and I looked at him and I said, well, you know what this might lead to? And he said, I certainly hope so. [Laughter.] And I said, well, you know-I shouldn't say this, this is our private conversation-I said, you know, it really isn't an accident that nobody else has ever tried to do this. [Laughter.] It's not an accident. This is not going to be one of those freebies, you know. [Laughter.]

And he began to talk about his sister who died of lung cancer, and how much he loved his sister. We've had so many conversations about his sister that-not just about this, but about her life, the fact that she was one of the very first Peace Corps volunteers-that I feel almost that I know her personally. And I could see in his eyes this determination to redeem the promise of her wonderful life. And I would also like to thank Nancy Gore Hunger's husband, Frank Hunger, who now serves as our Assistant Attorney General for the civil division. Thank you for being here, Frank. I know this is a great day for you.

I'd like to thank my wife, who has been talking to me about this issue for 20 years; and my wonderful daughter [Chelsea], who convinced my mother to quit smoking on her [Chelsea's] eighth birthday-something I was never able to do.

So each of us has a personal journey here that has brought us to this point. But today we are here as a nation, to try to help our parents do a better job in raising their children to be strong and healthy and good citizens, and to do our duty in that regard. We've tried to do a lot of things to help our kids over the last four years, and to help parents raise their children. We've worked hard on cultural issues, supporting things like the V-chip and educational television.

We had a big increase in support for anti-drug programs in our schools and for drug treatment. And we vetoed efforts to reduce those, although we should be investing more. We have a zero tolerance policy to keep guns out of school; we're requiring our states to enforce anti-drinking and driving laws; we defended drug testing cases involving student athletes; we've worked to bring grder and discipline into our children's lives bycencouraging and giving support to communites that try things like community-based cu墕ews and school uniforms and tougher enforcement of truancy laws.

We know, however, that in spiteofof all the things that are going right $\frac{}{0}$ in this country - with the economy up and nore jobs, with the crime rate down, with fewespeople on welfare and food stamps, dramaticolly higher percentage of our young $\vec{c}$ children immunized-that we have continued to see substantial rises in tobacco and $\vec{c}$ drug use among our young people.... [An\& children who] smoke cigarettes are much mofife likely to engage in other risky behavior, incheiding the use of marijuana and cocaine.

i

So we have to keep pressing forward to deal with these challenges, every one of them. And I want to thank General McCaffrey for being willing to give up his four stars and ngagnificent campaign to take on the drug fight Wor America's children and America's future. I th

Today we are taking direct action ${ }^{-1}$ protect our children from tobacco and espescially the advertising that hooks children on a roduct. I hear from time to time politicians sait that they don't really think advertising has mach to do with it. And whenever I hear one say that, I say, well, how come we're all spendingu so much money advertising when we run for office then? [Laughter.] If it's immaterial, let's jus: pull it all off and see what happens to us. [Laifghter.]

Cigarette smoking is the most significant public health problem facing our pe ple. More Americans die every year from smoking-related diseases than from AIDS, car caccidents, murders, suicides, and fires comboned. The human cost doesn't begin to calculage the economic costs-the thing that galvalized the legal claims of the Attorney Geperals, the absolutely staggering burdens on the-American healthcare system and on our economyen general.

But make no mistake about it, the human cost is by far the most important $\$$ sue. For every day, even though it's illegal, 3900 of our young people start smoking, and $10 Q 0$ of them will die earlier than they would otherwise die as a result. The vast majority of people who smoke in America today started when they were teenagers. If they don't start smoking when they're on a schoolyard, it's very likely they never will.

This epidemic is no accident. Children are bombarded daily by massive Mnarketing campaigns that play on their vulnorabilities, their insecurities, their longings to be something in the world. Joe Camebpromises that smoking will make you coo $\overrightarrow{\mathbb{D}}$ Virginia Slims' models whisper that smokingw will help you stay thin. T-shirts and sports spensorships send the message that healthy and vigorous people smoke and that smoking is fugh.

A year ago this month, we lamnched a comprehensive strategy to kick toba\&co out of the lives of our children. We proposed strong restrictions on advertising, marketing and sales of cigarettes to children. In the year that followed, the FDA received a torrent of 
comments from the public-more than 700000 - by far the largest outpouring of public response in the FDA's history. The FDA has heard from doctors, scientists, tobacco companies, and tens of thousands of children. We have carefully considered the evidence. It is clear that the action being taken today is the right thing to do, scientifically, legally, and morally.

So today we are acting. First, young people will have to prove their age with an ID to buy cigarettes. Second, cigarette vending machines will be banned from anywhere children and teenagers can go. Third, children will be free of tobacco advertising on billboards near their schools and playgrounds, and billboards in other locations will be restricted to black-andwhite, text-only messages. Fourth, if a tobacco ad is in a publication children and teenagers are likely to read, it also has to be black and white with no pictures. Fifth, companies will no longer be permitted to target young people with marketing gimmicks like T-shirts and gym bags. Sixth, cigarette companies may no longer use brand names to sponsor tennis tournaments, auto races and other sporting events.

Finally, the FDA will soon take steps to require the tobacco industry to educate our children about the real dangers of smoking. There is abundant evidence ... that a lot of young people simply don't believe there's any risks to their health.

With this historic action we are taking today Joe Camel and the Marlboro Man will be out of our children's reach forever. [Applause.]

I want to be clear-we've said it before, let's say it again-cigarettes are a legal product for adults. They have a perfect right to decide whether to smoke. There are many, many good people who have been farming, growing tobacco for generations in their families. They have a right to make a living for themselves and their families, and they will continue to do so. But let's be honest: we hope that over the long run, if we can dramatically reduce rates of smoking among children, the overall consumption of cigarettes will decline. If that happens, these good people who farmed the land and worked hard should not be left behind. And all 응 of us who have sought this course have a responsibility to help them if they face difficulties. [Applause.]

The cigarette companies still have a right to $\stackrel{\mathrm{O}}{=}$ market their products to adults. But today we $\overrightarrow{\vec{s}}$ are drawing the line on children, fulfilling our obligation as adults to protect them from influ- 등 ences that too often are stronger than they are. $\frac{\overline{\bar{N}}}{\bar{\alpha}}$

As I said before, I want to say again, this $\underset{\mathbb{Q}}{\mathscr{Q}}$ action is a tribute to so many of you who are here today. To the parents, the teachers, the doctors, the public officials. Dr [Lonnie] Bristow [immediate past president of the $\vec{\omega}$ American Medical Association], I particularly want to commend the AMA for its writings in $\vec{?}$ its journal, its relentless efforts to educate the $\omega$ American people through the physicians of this country. But I'd like to pay special tribute to oึ the children of America who have joined this crusade, who have organized and led a massive $\vec{c}$ grass-roots movement throughout America to $\mathbb{D}$ educate and inform people about the dangers of tobacco smoking for children.

They've staged teach-ins and "Kick Butts" days all across the country. They have used $\vec{\bullet}$ positive peer pressure on people who could[n't] care less what a lot of us old fogies think to teach their fellow students that smoking is not cool. So I want to thank these children for the work they have done to save their generation. [Applause.]

A lot of the work we do around here we know will only be fully manifest in people's lives in 욱 the future. We know we can't guarantee the success of any individual or family, but we have to guarantee them the tools and conditions that will enable them to make the most of their own lives. Today we take a real step to make sure that they have those lives in full measure. We have today met our responsibility to help our country protect its values, protect its children, and ensure its future.

Thank you all for what you've done. [Applause.]

\section{Regulations restricting the sale and distribution of cigarettes and smokeless tobacco to protect children and adolescents (executive summary)}

\section{Introduction}

With the August 1996 publication of a final rule on tobacco in the Federal Register, the Food and Drug Administration (FDA) will regulate the sale and distribution of cigarettes and smokeless tobacco to children and adolescents. The action results from the agency's assertion of jurisdiction over tobacco products. This was based on an intensive FDA investigation of the tobacco industry, tobacco use and its health consequences. The rule will prohibit the sale of cigarettes and smokeless tobacco to those under 18 while leaving them on the market for adults.
Tobacco use is the single leading preventable cause of death in the United States. ${ }^{1}$ It kills $\frac{0}{0}$ more than 400,000 Americans each year ${ }^{2}-\frac{D}{\mathbb{D}}$ more people each year than AIDS, car $\frac{\rho}{D}$ accidents, alcohol, homicides, illegal drugs, suicides, and fires, combined. ${ }^{3}$

The use of tobacco products, and the result- $\frac{8}{8}$ ing nicotine addiction, begins predominantly in children and adolescents and is, 윽 consequently, a pediatric disease. Approximately 3 million American adolescents currently smoke, and an additional 1 million adolescent males use smokeless tobacco. ${ }^{4}$ Each year, another 1 million 
young people become regular smokers. ${ }^{5}$ Approximately one out of every three of these young people will die prematurely as a result. ${ }^{6}$

Studies suggest that anyone who does not begin to use tobacco as a child or adolescent is unlikely to start as an adult. Eighty-two percent of adults who ever smoked had their first cigarette before age 18 , and more than half of them had already become regular smokers by that age. ${ }^{7}$ Among smokers ages 12 to 17 years, 70 percent already regret their decision to smoke and 66 percent say that they want to quit. ${ }^{8}$

Furthermore, studies show that children and adolescents are starting to smoke at earlier and earlier ages. ${ }^{9}$ Data reported in December 1995 showed that the proportion of 8 th- and 10thgraders who reported smoking in the 30 days before the survey had risen by one-third since 1991, to about 19 percent and 28 percent respectively. ${ }^{10}$

Similar problems exist with underage use of smokeless tobacco. School-based surveys in 1991 estimated that 19.2 percent of 9 th- to 12th-grade boys use smokeless tobacco. ${ }^{11}$

Finally, studies show that young people do not fully understand the serious health risks of these products, or believe that those risks do not apply to them. They are also very impressionable and therefore vulnerable to the sophisticated marketing techniques employed by the tobacco industry, techniques that associate the use of tobacco products with excitement, glamour, and independence.

The wealth of information assembled by the agency about nicotine's addictive properties led FDA to conclude that it has jurisdiction over tobacco products. The age of onset of nicotine addiction, and its well-known consequences, suggested the best way for the agency to regulate tobacco to protect the public health.

Of the fifty million ${ }^{12}$ people who smoke cigarettes, 77-92 percent are addicted. ${ }^{13}$ Because an outright ban of tobacco products could have profound health consequences for these tens of millions of addicted smokers, FDA has chosen instead to focus on preventing children and adolescents from becoming addicted to these products in the first place. Evidence in the administrative record (the collection of documents gathered by FDA during its investigation and made publicly available) demonstrates that the most effective way to achieve this goal is to limit the access to, and appeal of, cigarettes and smokeless tobacco to children and adolescents.

Specifically, the rule makes the sale of cigarettes and smokeless tobacco to children and adolescents, anyone younger than 18 years of age, a federal violation. In addition, the rule requires manufacturers, distributors, and retailers to comply with certain conditions regarding the sale, distribution and promotion of tobacco products. It prohibits all free samples and limits retail sales in most circumstances to face-to-face transactions. As a result, vending machines and self-service displays are prohibited, except in facilities where the retailer or operator ensures that no person younger than 18 is present or is permitted to enter at any time.
The rule limits advertising generally to a black-and-white, text-only format 앙 ensure that advertising is not used to create demand for these products among young geople and thus undermine the restrictions on $\overrightarrow{\mathrm{g}}$ cess. Billboards and other outdoor adventising are prohibited within 1,000 feet of sẹtools and public playgrounds. The sale and distribution of non-tobacco items, such as haws and tee shirts that carry cigarette logos, sfegch as Joe Camel, are prohibited, and spon $\$$ orship of sporting and other events is limitedgo the corporate name only.

\section{Background}

$\vec{\circ}$

The Food and Drug Administration to regulate tobacco products on fugust 10 , 1995. This proposed rule, which wașpublished in the Federal Register on August 19y, resulted from a more than yearlong invesflgation by FDA into the role that nicotine plays in tobacco products, patterns of tobac $\overrightarrow{E S}$ product use, and the role of advertiging and promotional practices in young people's decision to use tobacco products.

From publication of the proposed rule in August 1995 until January 1986, FDA accepted comments from the public oReactions came from many sections of society including the tobacco and advertising industries, medical and public interest groups, and indipidual citizens. FDA reopened the commentoperiod for one month from mid-March to min-April to accept public comments on specific ocuments that were added to the public recorch

The agency received more comments on the proposed rule - some 700,000 pieces of mailthan at any other time in the historyof federal rule making. Both supporters and @pponents organized campaigns to generate reactions to the proposed rule; the agency iden fified more than 500 different types of form letters. One massive campaign, which opposed the rule, generated over 300,000 pieces of -mail-42 percent of all the mail received. So 95 e 95,000 people, including more than 35,008 children, sent individual views. The Fchildren's comments were overwhelmingly sapportive. The largest single comment, submitsed by the cigarette industry, consisted of appoximately 45,000 pages.

Although many of the comments were addressed to specific provisions of the proposed regulation, tens of thokpsands of letters contained general commexts. Many expressed strong overall opposition the rule; many others expressed strong $\stackrel{\Phi}{\Phi}$ support. Comments came from every corner of the country, from federal, state ford local government officials, from smoker\$ who felt the government was inappropriatelyơmeddling in their lives, and from smokers desperate, but unable, to quit. The agency hearard from employers and employees in the affected industries, including tobacco farmes s, wholesalers, cigarette manufacturers, and laborers who fear that the regulation may cause the loss of their employment. One supportive letter came from a coalition of medical associations representing 125 groups with more than 18 
million members. Supporters and opponents alike agreed that children under age 18 should not use nicotine-containing tobacco products.

Some comments opposing the proposed rule argued that FDA should not regulate tobacco and should focus instead on its traditional responsibilities. Still others said FDA should not interfere with the free choice of adults, and some feared that the rule was just the first step toward a total ban. Additional comments opposing the proposed rule in general argued that there is no need to regulate tobacco because the products are already highly controlled.

In contrast, comments supporting the proposed rule said that existing tobacco regulations do not address the health consequences of tobacco, nor do they effectively prevent sales to minors. Many pointed out that tobacco use is the single most preventable cause of death in the United States, and that, because of the serious health risks associated with these products, it is essential that the government take action to reduce the number of young people who begin smoking or using smokeless tobacco. A number of comments indicated that children and adolescents are drawn to the images associated with smoking and that steps should be taken to prevent young people from being bombarded by these tobacco messages.

\section{Overview of Statutory and Constitutional Authority}

The federal Food and Drug Administration's authority to carry out its mission to protect the public health derives primarily from the federal Food, Drug, and Cosmetic Act (the act). ${ }^{14}$ This statute provides the agency authority to regulate a wide array of consumer products, including drugs and devices.

In order to assert jurisdiction over cigarettes and smokeless tobacco, these products must meet at least one of the definitions of a regulated product. As discussed thoroughly in the 1996 Jurisdictional Determination, ${ }^{15}$ FDA has concluded: (1) that cigarettes are "combination products," having both a drug component, including nicotine, and device components, namely processed tobacco, the ventilation system, and filters; and (2) that smokeless tobacco is a combination product that consists of a drug component, nicotine, and device components, specifically processed tobacco, and for some products, a porous pouch.

Congress gave the agency considerable latitude to decide whether to regulate drug/device combination products using the act's drug authorities, device authorities, or both. FDA has determined that tobacco products are most appropriately regulated under the device provisions of the act, including the restricted device authority in section 520 (e) of the act, which allows the agency to impose restrictions on the sale, distribution, and use of a product.

During the public comment period, some opponents challenged FDA's legal authority to impose the proposed restrictions, arguing that the agency's action would violate various laws and parts of the Constitution, including the Separation of Powers and Nondelegation doc- trines, and the First, Fifth, Ninth and Tenth Amendments. After carefully considering these $\mathrm{O}$ arguments, the agency has concluded that the statutory and constitutional bases of FDA's jurisdiction and regulation are sound.

\section{The Rule}

The provisions of the rule are based on the agency's investigation of tobacco products and nicotine's addictiveness, the evidence in the public administrative record, and the review on and consideration of the comments received on $\overrightarrow{0}$ the proposed rule. In some instances, that review strengthened FDA's original position; in others, it caused the agency to either eliminate or modify some provisions.

1. RESTRICTING ACCESS TO CHILDREN AND ADOLESCENTS

The rule makes the sale of cigarettes and smokeless tobacco products to children and $\vec{c}$ adolescents younger than age 18 a violation of $\mathbb{D}$ federal law. Currently, young people purchase $\mathbb{\mathbb { D }}$ an estimated $\$ 1.26$ billion of tobacco products annually. ${ }^{16}$ Despite laws in all 50 states that prohibit sales to minors, numerous studies $\vec{\theta}$ show that adolescents have little difficulty pur- of chasing tobacco products. The 1994 Surgeon General's report examined 13 studies of over-the-counter sales and determined that approximately 67 percent of minors were able to purchase cigarettes illegally. ${ }^{17}$ Significant $\stackrel{\unrhd}{\mathbb{Q}}$ numbers of young people successfully purchase smokeless tobacco as well, with 90 윽 percent of smokeless tobacco users in junior high and high school saying they buy their own smokeless tobacco. ${ }^{18}$

Other studies indicate that actively enforced access restrictions have been effective. For example, a comprehensive community intervention in Woodridge, Illinois, involving retailer licensing, regular compliance checks, $\overline{\overline{ }}$ and penalties for merchant violations, reduced illegal sales from 70 percent to less than five percent in under two years. ${ }^{19}$ Rates of both $\delta$ experimentation and regular smoking decreased more than 50 percent among seventh 옥 and eighth grade students in this community.

This study, as well as other studies reviewed by FDA, led the agency to draft a comprehen- N sive proposal to reduce young people's access to cigarettes and smokeless tobacco, and to $\mathrm{N}$ make explicit the responsibility of manufactur- $\omega$ ers, distributors, and retailers to prevent cigarette and smokeless tobacco product sales to persons $\stackrel{\varrho}{\simeq}$ under 18 years of age. The access portion of the rule has several major provisions, including:

\section{a. Minimum Age}

The regulation prohibits retailers from selling cigarettes and smokeless tobacco to anyone younger than 18 years of age. Retailers must verify that purchasers are 18 or older by check- $\delta$ ing identification that includes the bearer's date of birth and photograph. The rule requires retailers to check the identification of anyone 26 or younger. Acceptable identification could include a driver's license or college identification card. 
The need for this provision is supported by studies indicating that minors who purchase cigarettes and smokeless tobacco from stores are rarely asked for identification. One study found that 67 percent of teenagers, whose mean age was 15 years, were asked no questions when they attempted to purchase cigarettes. ${ }^{20}$

\section{b. Minimum Package Size}

Under the rule, retailers are prohibited from opening any cigarette package or smokeless tobacco product to sell or distribute individual cigarettes or smaller amounts of tobacco. ${ }^{21}$ In addition, the regulation establishes 20 cigarettes as the minimum package size. Both provisions are designed to prevent the kind of sales that are attractive to young smokers - small, inexpensive, easy to conceal "kiddie" packs.

Although kiddie packs have only recently begun appearing in the United States, studies in countries where they have been available show that kiddie packs are preferred by adolescents far more than by adults. For example, one study in Australia showed that 56.3 percent of all 14 to 15 year old smokers had purchased kiddie packs in the month prior to the survey, compared with only 8.8 percent of adult smokers. ${ }^{22}$

\section{c. Vending Machines}

The rule bans the use of vending machines in almost all circumstances. Vending machines represent one of the major ways that children currently obtain cigarettes. Numerous studies and surveys show that significant percentages of young people are able to purchase cigarettes from vending machines, even in areas that have laws restricting the placement of those machines or requiring the use of locking devices.

The 1994 Surgeon General's Report examined nine studies of vending machine sales and found that children and adolescents successfully purchased cigarettes from vending machines 88 percent of the time. ${ }^{23}$ In addition to studies demonstrating how easily children can purchase cigarettes from vending machines, the proposed rule cited surveys of children's actual purchasing behavior. Vending machines are most popular with the youngest smokers, with 22 percent of 13 year olds who smoke purchasing cigarettes from them compared with 2 percent of 17 year olds. ${ }^{24}$

The provision to eliminate the use of vending machines generated numerous comments. Comments in opposition argued that the provision would be unnecessary if state and local governments enforced existing laws prohibiting the sale of tobacco products to children under the age of 18 . They also argued that most vending machines are located in areas that are off-limits to children, such as night clubs or casinos, or in areas that children rarely frequent, such as industrial plants and private offices.

Conversely, nearly all comments in favor of the provision argued that vending machines, including those in "adult-only" locations and those with locking devices, offer children easy access to tobacco products. Tens of thousands of school children wrote letters asking that vending machines be eliminated.
FDA has decided that cigarettes and smokeless tobacco should not be sold frow vending machines except in those limited 18cations in which the retailer or operator ensuges that no person younger than 18 is present of permitted to enter at any time. This exception.to the ban on vending machines is intended to and carefully circumscribed.

While the agency agrees that sonat children who are determined to use cigärettes or smokeless tobacco may find or creat ${ }^{\text {new }}$ nays of obtaining them, FDA has concluded that the removal of vending machines from sites accessible to young people will eliminale what is currently a popular and easy means of access to tobacco, especially for younger cripldren. In addition, if other access restriętions are imposed, such as requiring customers to provide proof of age, without also Efiminating vending machines, use of vending machines among children and adolescents would likely increase. Therefore, the agency has çoncluded that the provision is an important part of the overall effort to reduce children's cigarettes and smokeless tobacco.

FDA will monitor compliance with the provisions governing vending maching for two years and will propose additional re@rictions if there is evidence at that time that young people are continuing to purchase tobaccQ products from these machines.

\section{d. Self-Service Displays}

The rule also bans the use of B]lf-service displays of tobacco products, with certain exceptions, ${ }^{25}$ to prevent young pesple from helping themselves to these products: This will reduce the likelihood of theft and i $\overrightarrow{p c r e a s e}$ the involvement of sales clerks in transa\&tions with young people. Self-service displays permit children and adolescents to quickly, \&asily, and independently obtain cigarettes and smokeless tobacco. A study by the National Aeademy of Sciences' Institute of Medicine found that over 40 percent of grade school students who smoked daily shoplifted cigarettes at some time, from self-service displays. ${ }^{26}$ One study found that tobacco sales to minors dropped 40 to 80 percent after enactment of ordinances prohibiting self-service displays an requiring vendor-assisted sales. ${ }^{27}$ In addipion, the Institute of Medicine reported that placing products out of reach "reinforces thes message that tobacco products are not in thegrame class as candy or potato chips."28

\section{e. Mail Order Sales and Redemption of Coupons}

The proposed rule would have probibited the

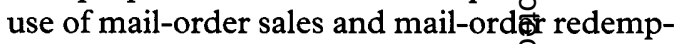
tion of coupons because there is foliable way to verify the consumer's age. A the time FDA issued the proposed rule, the standard

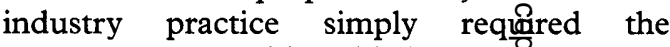
consumer to provide a birth date box to signify that he or she was of gal age.

The agency received many comments on this provision. Opponents argued that young people do not buy cigarettes through the mail because they do not have checks or credit cards 
with which to pay for them. Many adults stated that they prefer mail-order sales because the products are unavailable in stores or are less expensive. Others said mail order sales serve those in rural or isolated areas, and that the rule would eliminate the principal or sole source of tobacco for those adults.

After reviewing the comments, FDA decided to allow mail order sales of tobacco products. There is little or no evidence to show that young people use mail order sales to any significant degree.

However, the agency is concerned that children and adolescents may turn to mail order sales if access to tobacco products is denied in other ways. Therefore, FDA will monitor mail order sales to ensure that they do not provide young people with a mechanism for purchasing cigarettes and smokeless tobacco.

Mail-order redemption of coupons for free cigarettes or discounted cigarettes will not be permitted on the basis that the agency did receive evidence that young people were able to obtain free samples in this manner. Evidence from the attorney general of Massachusetts showed that as part of an operation conducted by his office, 30 young people mailed in coupons for free samples of smokeless tobacco. Virtually all of them received their free samples in the mail. ${ }^{29}$

Contrary to the concerns expressed by a number of adults, this provision does not prevent adults from receiving coupons through the mail as long as they redeem the coupons in person where a sales clerk can verify the customer's age.

\section{f. Free Samples}

The regulation prohibits the distribution of free samples of cigarettes or smokeless tobacco. Free samples are often distributed at "mass intercept locations," such as street corners and shopping malls, and at events such as festivals and concerts. Free samples represent a "risk-free" and "cost-free" way for young people to obtain cigarettes or smokeless tobacco. Surveys and reports demonstrate that young people can obtain free samples easily in spite of voluntary industry codes. For example, one survey in New Jersey found that one-third of approximately 500 high school students who were current or former smokers reported receiving free cigarette samples before the age of $16 .^{30}$

A few comments opposed any restrictions on free samples, claiming that eliminating free samples would violate the rights of adult consumers, reduce choices for adults, or deprive adults of an opportunity to save money. In contrast, many comments, including several that opposed the remainder of the rule, supported a ban on free samples. Comments cited instances where young people easily obtained free samples of cigarettes and smokeless tobacco.

While the ban on free samples will affect adults, no suggestions were made on how to prevent free samples from reaching young people. The agency determined that the benefits gained from eliminating free samples for young people outweigh any inconvenience to adults.

2. REDUCING APPEAL OF ADVERTISING TO CHILDREN AND ADOLESCENTS

In August 1995, FDA announced its proposal $\stackrel{\overrightarrow{0}}{.}$ to restrict cigarette and smokeless tobacco advertising in ways that would reduce the $\frac{\infty}{0}$ appeal of such ads to children and adolescents. FDA's purpose in proposing the advertising $\frac{\bar{\sigma}}{\overline{0}}$ restrictions was to ensure that the access restrictions are not undermined by advertising $\varrho$ that heightens the appeal of cigarettes and smokeless tobacco to young people. The $\overrightarrow{0}$ proposed rule included a range of restrictions $\overrightarrow{\vec{\omega}}$ that attempted to preserve the components of $\omega$ advertising and labeling which can provide $\stackrel{?}{?}$ product information for adult smokers, while or eliminating the imagery and color that make is advertising appealing to children and adolescents.

Briefly, the final regulation generally limits tobacco advertising in all existing media forms $\$$ to a black-and-white, text-only format. $\frac{\mathbb{D}}{1}$ Outdoor advertising is prohibited within 1,000 feet of public playgrounds, elementary schools or secondary schools. Advertisements in publications read primarily by adults and advertisements placed in adult-only locations are exempt from any advertising restrictions.

Tobacco companies will not be permitted to sell or distribute promotional items such as tee shirts, caps, and sporting goods identified with tobacco products, for example through use of a brand name or logo. Similarly, logos, brand names, and other identifiers of tobacco products cannot be used in sponsorship of musical, cultural, and other events or on teams and entries. However, sponsored events and entries in the name of a tobacco company may continue.

Tobacco products are among the most heavily advertised in this country, accounting for advertising and promotional expenditures of more than $\$ 6$ billion in $1993 .{ }^{31}$ Studies show that tobacco advertising significantly influences children and adolescents in their decision to start smoking or using smokeless tobacco, and it must be considered in any serious effort to reduce tobacco use among youth.

This aspect of FDA's proposal produced substantial comment that either praised the o proposed restrictions as critical to reducing the $N$ numbers of children and adolescents who N begin using tobacco or attacked the advertising provisions as unwise and unconstitutional. Based on its review of the comments, studies, surveys and expert opinion, the agency has? refined some of the advertising restrictions to ensure that they are narrowly tailored to achieve FDA's public health objectives.

\section{a. Impact of Advertising}

FDA relied heavily on two reports that summarized the evidence concerning the effect of advertising on young people's tobacco use. One came from the Institute of Medicine, and the other was the 1994 Surgeon General's Report. Both reports concluded that advertising was an important factor in young 
people's tobacco use, and that restrictions on advertising must be part of any meaningful approach to reducing smoking and smokeless tobacco use among young people.

In reviewing the literature, FDA found hundreds of studies examining psychological and social factors affecting tobacco use. These studies were conducted by noted researchers in the fields of medicine, psychology, marketing, public health, and other disciplines, and were published in respected, peer-reviewed scientific journals. Overall, the research provides strong evidence that restrictions on the advertising of cigarettes and smokeless tobacco will serve to protect the health of children and adolescents.

Collectively, the studies show that children and adolescents are widely exposed to, aware of, respond favorably to, and are influenced by cigarette advertising. One study found that 30 percent of 3 year olds and 91 percent of 6 year olds identified Joe Camel as a symbol for smoking. ${ }^{32}$ Other studies have shown that young people's exposure to cigarette advertising is positively related to smoking behavior and their intention to smoke. Still others have suggested that cigarette advertising helps young people to decide what is normal or socially acceptable behavior, and that those who overestimate the prevalence of smoking seem to be more likely to begin smoking and progress to regular smoking. Finally, brand advertising appears to be particularly effective with children and adolescents. The three most heavily advertised brands are smoked by 86 percent of young people who smoke; by contrast, adults are far more likely to choose one of the "generic" brands, which are advertised less. ${ }^{33}$

The tobacco and advertising industries were critical of FDA's proposed regulation, focusing their criticism on the failure of the evidence to establish empirically that advertising causes young people to use tobacco, or on whether each proposed restriction would substantially reduce young people's smoking and use of smokeless tobacco. Moreover, they argued that FDA should not eliminate imagery and color since these are essential elements of effective advertising to adults.

In contrast, a comment from the nation's largest psychological association contended imagery and color in advertisements should be eliminated because of their effectiveness in appealing to children. The comment maintained that children generally have less information-processing ability than adults, are less able or less willing to heed the factual information in advertisements, and are less motivated to carefully consider information such as tar and nicotine content or the Surgeon General's warnings in cigarette and smokeless tobacco advertising.

In the final regulation, FDA narrowed the advertising restrictions as much as possible to retain the informational value that advertising has for adults. Information regarding price, tar and nicotine levels, and taste, information typically important to adults who smoke, can be communicated effectively to adults through words alone.

\section{b. The First Amendment}

Those opposed to the regulation cridicized the proposed rule for violating the First Amendment and understating the gprotection that commercial speech is afforded. of this contention, their comments not only relied on traditional First A $\overrightarrow{\text { Thendment }}$ jurisprudence, but cited as well to fwo recent cases, Rubin v. Coors, 115 S. Ct. 1585 , and 44 Liquormart, Inc. v. Rhode Island, $16 \mathrm{~S}$. Ct. 1495 (May 13, 1996). FDA i $\vec{\phi}^{2}$ no way underestimates the protection affoted commercial speech, and did weigh its proposal against the Supreme Court's recen $\overrightarrow{P r u l i n g s}$ in deciding on the provisions of the final rule.

Other comments maintained that tobacco advertising concerns unlawful activity and that therefore it is not protected by ${ }_{\omega}^{\mathrm{w}}$ the First Amendment. These comments pisinted out that it is unlawful in all 50 states to wll tobacco to children under the age of 18. Spponents argued that it is lawful for adults to buy tobacco, and therefore the advertisiffor for those products cannot be considered to be unlawful. Based on its consideration of these grguments, FDA found that a credible basiop exists on which to conclude that, at least to the extent that tobacco advertising is relatededo sale of these products to children under 18 , it is not speech protected by the First Amen

However, the agency did nof rest.its regulation solely on this ratiogale, but considered whether the rule Peets the standards for regulating commer fal speech under the three-prong test estaß) Central Hudson Gas and Electric Co $\overrightarrow{p p}$. v. Public Service Commission of New York. ${ }^{34}$ THe agency's analysis under each prong is provided below.

(1) Is the government's interest $\overrightarrow{\text { gibstantial? }}$ Tobacco use is the leading cause of Areventable death in the United States. More than 400,000 people die each year from tobasco-related illnesses. ${ }^{35}$ Most people who become addicted to cigarettes begin smoking beforethey reach the age of $18 .{ }^{36}$ Of the one million ple who become regular smokers each year, a third will die prematurely as a result from tobacco use. ${ }^{37}$ Even those who obposed the regulation did not seriously conteşt that the government had a substantial witerest in protecting the health of individuals్ under 18 years of age.

(2) Do the regulations directly afvance the government's interest? Some స્心omments asserted that the agency needso to prove conclusively by empirical evidene that the restrictions that it enacts will comptetely solve the problem of youth tobacco use. The agency found, based on the available evidence, expert opinion, surveys, and studies, that $\mathbb{\sigma}_{\text {dvertising }}$ plays a material role in children's tofocacco use, and that the regulation will contfibute to a reduction in young people's use of tobacco.

(3) Are the provisions of the reghlation are narrowly drawn? Comments opposing the proposed restrictions asserted that tomeet this requirement, the restrictions must be the "least restrictive means" available. In contrast, a number of comments said that to satisfy this requirement, the restrictions must accomplish 
a "reasonable fit" between the regulation and the governmental interest to be served. The agency agreed with the latter interpretation, and found that its regulation meets this requirement by restricting only those elements of advertising and promotion that affect young people, while preserving those aspects of advertising that provide information to adults.

\section{c. Major Advertising Provisions}

The advertising portion of the final rule contains several major provisions including the following:

\section{Billboards Near Schools and Playgrounds}

Tobacco advertisements on billboards and other outdoor advertising are prohibited within 1,000 feet of elementary and secondary schools and public playgrounds. These are places where children and adolescents spend a great deal of time, and, thus, where they can be influenced by exposure to advertising.

Some comments asserted that young people do not pay attention to billboards. Other comments said that billboards are unavoidable and should be banned everywhere, not just within 1,000 feet of schools and playgrounds. Evidence of the unavoidability of billboards was found in the outdoor industry's own marketing materials on outdoor advertising, which stated: "Outdoor is right up there. Day and night. Lurking. Waiting for another ambush." 38 However, because of the agency's determination to ensure that its regulations are narrowly tailored, it did not accept these comments.

Moreover, evidence provided in part by the tobacco industry supports the importance of billboards as advertising vehicles for young people. One survey conducted by BKG Youth for Advertising Age showed that 46 percent of children eight to 13 years old said they most often saw cigarette advertising on billboards, out pacing magazines. ${ }^{39} \mathrm{~A}$ study conducted by the R.J. Reynolds Tobacco Company reported that 51 percent of $10-17$ year olds surveyed said that they had seen or heard of Joe Camel from a billboard advertisement. ${ }^{40}$

\section{Text-only Format}

The final rule limits cigarette and smokeless tobacco advertising to black text on a white background, eliminating the imagery and color young people find so appealing. There are, however, two exceptions in which color and imagery in tobacco advertisements are permitted: publications with a primarily adult readership, and adult-only facilities. Adult publications are defined as those: (1) whose readers age 18 or older constitute 85 percent or more of the publication's total readership, or (2) that are read by two million or fewer people under age 18. Based on current readership figures, publications such as Rolling Stone and Sports Illustrated would be limited to text-only advertisements, while Time and Newsweek would be free from restrictions. ${ }^{41}$

Those objecting to this provision said that the text-only restriction was a pretext to banning cigarette advertising generally, and that cigarette advertising does not cause children to start smoking. In contrast, nearly three-quarters of those supporting the text-only provision primarily argued that such action was needed to eliminate the appeal of tobacco products, and that the advertising makes tobacco use more appealing to children and adolescents. The text-only provisions apply to traditional media such as magazines, newspapers and billboards, as well as to direct mail.

\section{Sale and Distribution of Non-tobacco Items and Services}

The final rule prohibits the tobacco industry from disseminating any non-tobacco item or service that identifies it with tobacco products. This requirement is intended to include such items as tee shirts, caps, sporting goods, and other items that display cigarette brand names or use other ways to connect them with tobacco products. Promotional items are advertisements for these products and very often end up in the hands of young people. A 1992 Gallup survey found that about half of adolescents who smoke and one quarter of adolescents who do not smoke owned at least one of these items. ${ }^{42}$

The agency concluded that a ban of these items was necessary in order to eliminate the appeal that these objects have for young people and to prevent wearers or users of these items from becoming walking advertisements. In addition, the rule prevents a company from offering any gift or item (whether identified with a tobacco brand or not) to any customer. This is essential to prevent the something-fornothing appeal that such "free" products have for young people.

FDA originally proposed to prohibit the tobacco industry from running contests, lotteries, or games of chance. Because contests, lotteries, and games of chance are already limited to those over 18 , and cannot be based on the purchase of a product, the agency has made a change and is not prohibiting them in the final regulation. However, they must follow the rules for advertising and appear in black text on a white background.

\section{Sponsorship of Events}

The final rule permits tobacco companies to sponsor events, entries, and teams in the corporate name. However, it prohibits tobacco companies from sponsoring any sporting, cultural, or other event in the brand name, logo, colors or anything else that would associate it with particular cigarettes or smokeless tobacco products. In addition, the final rule has been modified to also prohibit tobacco brand name sponsorship of race cars as well as other teams or entries.

Studies show that tobacco-brand sponsorship associates tobacco use with exciting, glamorous, or fun events, such as car racing and rodeos. It also provides an opportunity for "embedded advertising" that actively creates a "friendly familiarity" between tobacco and sports enthusiasts, many of whom are children and adolescents. 
The leading source for television viewership estimates that auto racing is watched 64 million times a year by those younger than $18 .^{43}$ And unlike print advertisements, which are typically seen for a few seconds, sponsored events with the brand name are viewed for hours at a time.

Further, auto racing, a primary type of tobacco-sponsored event, is becoming increasingly popular with young people, as other corporate sponsors have discovered. According to the president of Hanna-Barbera Cartoons, Inc., the creator of The Flintstones and other cartoons, who recently began sponsoring the "Wacky Racing Team" in the NASCAR Winston Cup Series, "In NASCAR we found a great kids business." ${ }^{44}$ Finally, race car drivers are extremely popular with young people and often are looked up to as heroes. ${ }^{45}$

\section{EDUCATING YOUNG PEOPLE ABOUT HEALTH RISKS}

FDA proposed to require tobacco manufacturers to establish and fund a national public education program to counter the effects of the pervasive advertising that for decades has influenced young people to begin and continue using tobacco products.

This approach was based, in part, on historical experience. From July 1, 1967 to December 31, 1970, the Federal Communications Commission, as part of the "Fairness Doctrine," required broadcasters to provide a significant amount of time for anti-smoking messages on television and radio. One anti-smoking message appeared for every three or four industry-sponsored, cigarette advertisements until a ban on all cigarette advertisements on television and radio became effective on January 1, 1971.

For several years, the American public was exposed to both pro- and anti-smoking messages. During this time, per capita cigarette consumption declined 7 percent, from 4,280 in 1967 to 3,985 in $1970 .{ }^{46}$ Most of the 7 percent decline (4.5 percent) was attributable to the anti-smoking messages. This was the first time since the early 1930's that per capita consumption declined consecutively for 3 years, and was one of the largest declines ever recorded. Additionally, a study of nearly 7,000 adolescents found that adolescent smoking rates declined during this period. ${ }^{47}$ When the anti-smoking messages ended on television and radio, per capita cigarette consumption began to rise.

FDA received many comments on the proposed educational campaign, with the majority favoring the provision. They raised many issues concerning the administration of the program as proposed, including, for example, whether the proposed funding would be equitable or sufficient, and whether industry's level of involvement would jeopardize its effectiveness.

After considering the comments, FDA determined that educating children and adolescents about the unreasonable risks these products pose is analogous to the notification it has required for other devices under section 518(a) of the federal Food, Drug, and
Cosmetic Act. In section 518(a) of the act, Congress provided FDA with the althority to require device manufacturers to notify device users about unreasonable risks of substantial harm posed by a device in order tळ゙્ eliminate those risks.

The agency intends to initiate $\overrightarrow{\vec{A}}$ section 518(a) notification process by sencing letters to the six tobacco companies that se significant number of tobacco products to young people. These letters will explain why the agency believes that a national, molti-media campaign under section 518(a) educate young people is necessary to reduce the risks tobacco products pose. The letterș will also offer the companies the opportunity?to consult with FDA about the necessity, and the scope, of a notification campaign.

4. ADDITIONAL REQUIREMENTS

$\omega$ The agency proposed to take Gdditional regulatory action if significant reductions in use of cigarettes and smokeless tobafgco among young people were not met within se years. Based on the comments, the agency has decided to delete this provision. The agency will monitor the effectiveness of the regulations and the extent to which the \&ndividual provisions are followed.

\section{RELATIONSHIP BETWEEN REGULATIO AND} STATE LAWS

Under section 521 (a) of the act, stat@ and local requirements pertaining to the कssale and distribution of cigarettes and $\$$ mokeless tobacco that are different from, or addition to, the federal requirements, are preempted. Most of the state and local laws thatwould be affected are weaker, for example, state vending machine restrictions. State and boal laws unrelated to the rule, such as restropctions on smoking in restaurants, will not be affected. Under section 521(b), state find local governments can submit applications for exemptions from preemption, and FDA is prepared to consider any such applieteations it receives in an expeditious manner.

6. ANALYSIS OF ECONOMIC IMPACT

\section{으}

In financial terms, the rule is expected to produce significant health-related $\frac{D}{0}$ benefits, ranging between $\$ 28$ billion to $\$ 43$ bitlion each year. FDA estimates that the rule impose one-time costs of between $\$ 174$ andn $\$ 187$ million, and recurring annual operating costs of between $\$ 149$ and $\$ 185$ million. The agency calculated the economic benefits by \&્stimating how many adolescents would not stak smoking because of this rule, and then, usirfor existing risk data, predicted how much sictoness and death from tobacco products be prevented. The calculations estimatipg the cost of implementing the rule were gased on comments and several extensive cenomic reports from the affected industries gredicting the rule's impact.

7. IMPLEMENTATION

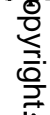

Most of the provisions of this rule go into effect one year after publication in the Federal Register. There are two major exceptions: (1) Six months after publication, retailers must 
begin enforcing the 18 -year-old minimum age of purchase provision by checking purchasers' identification; (2) because most sponsorship contracts are long term, companies will have two years to meet the sponsorship requirements which prohibit sponsorship of events in the name of a tobacco product.

1 Lynch, Barbara S., and Bonnie, Richard J., eds., Growing $U_{P}$ Tobacco Free: Preventing Nicotine Addiction in Children and Youths, Institute of Medicine, National Academy Press, Washington, D.C., 1994, p.3. (Hereafter referred to as IOM.)

2 "Cigarette Smoking-Attributable Mortality and Years of Potential Life Lost-United States, 1990," in $M M W R$, CDC, DHHS, 42(33):645-649.

3 IOM, op. cit., p. 3 .

4 Centers for Disease Control and Prevention, Preventing Tobacco Use Among Young People: A Report of the Surgeon General, U.S. Government Printing Office, Washington, D.C., 1994. p. 5. (Hereafter referred to as SGR 1994.)

5 IOM Report, op. cit., p. 8.

6 Memorandum from Michael P. Ericksen (CDC) to Catherine Lorraine (FDA) August 7, 1995, and CDC Fact Sheet; citing Pierce, J. P., M. C. Fiore, T. E. Novotny, E. J. Hatziandreu, and R. M. Davis, "Trends in Cigarette Smoking in the United States: Projections to the Year 2000", fAMA , 261:61-65, 1989; Unpublished data from the 1986 National Mortality Followback Survey, CDC, OSH Peto, R., A. D. Lopez, J. Boreham, M. Thun, and C. Health, Mortality from Smoking in Developed Countries, 1950-2000: Indirect Estimates from national Vita Statistics, Oxford University Press, Oxford, 1994.

71994 SGR, op. cit., p. 65 .

8 The George H. Gallup International Institute, Teenage Attitudes and Behavior Concerning Tobacco, September 1992. p 54

9 Cigarette Smoking Among Adults-United States, 1991 $M M W R$, DHHS, CDC, vol. 42, No. 12, pp. 230-233, 1993; Johnston, L. D., P. M. O'Malley, and J. G. Bachman, National Survey Results on Drug Use from the Monitoring the Future Study 1975-1993, vol. I: Secondary School Students, Rockville, MD, DHHS, PHS, National Institutes of Health (NIH), National Institute on Drug Abuse (NIDA) Health (NIH), National Institute on Drug Abuse (NIDA),
NIH Pub. No. 94-3809, pp. 9 and 19, 79, 80, 101, 1994, NIH Pub. No. 94-3809, pp. 9 and 19, 79, 80, 101, 1994;
Smoking Rates Climb Among American Teen-agers, Who Find Smoking Increasingly Acceptable and Seriously Underestimate the Risks, The University of Michigan News and Information Service, Table 1., July 17, 1995; Results from the 1995 Monitoring the Future Survey, National Institute on Drug Abuse Briefing for Donna E. Shalala, Secretary of Health and Human Services, December 13,1995.

10 Johnston, O'Malley, and Bachman, ibid.; Monitoring the Future Survey, 1995, ibid.

11 Kann, L. et al., Results from the National School-Based 1991 Youth Risk Behavior Survey and Progress Toward Achieving Related Youth Objectives for the Nation, Public Health Reports, vol. 108, (Supp.1), 1993. p. 47-54.

12 National Household Survey on Drug Abuse: Population Estimate 1993, Department of Health and Human Services Estimate 1993, Department of Health and Human Services Mental Health Services Administration (SAMHSA), Office of Applied Studies, Rockville, MD, Pub. No. (SMA) 94-3017, pp. 89 and 95, 1994.

13 Hughes JR, Gust SW, Pechacek TF. Prevalence of tobacco dependence and withdrawal. American fournal of Psychiatry, 1987; 144(2):205-8. ; Woody GE, Cottler LB, Cacciola J. Severity of dependence: data from the DSM-IV field trials. Addiction, 1993; 881573-9.; Cottler L Comparing DSM-III-R and ICD-10 substance use disorComparing DSM-III-R and ICD

1421 U.S.C. 201 et seq.

15 Nicotine in Cigarettes and Smokeless Tobacco Is a Drug and These Products Are Nicotine Delivery Devices Under the Federal Food, Drug, and Cosmetic Act: Jurisdictional Determination (the 1996 Jurisdictional Determination)

16 DiFranza, J. R., and J. B. Tye, Who Profits from Tobacco Sales to Children? $¥ A M A, 263(20): 2784-2787,1990$.

171994 SGR, op. cit. p. 249.

18 U.S. Department of Health and Human Services. Youth Use of Smokeless Tobacco: More Than A Pinch of Trouble. USDHHS, Office of Inspector General. Control No. P-06-86-0058, 1986

19 Jason, L.A., et al., Active Enforcement of Cigarette Control Laws in the Prevention of Cigarette Sales to Minors, fAMA, 266(22):3159-3161, 1991.
20 Erickson, A.D., et. al., A Baseline Assessment of Cigarette Sales To Minors In San Diego, California, fournal of Com- $-\overrightarrow{0}$ munity Health, 18(4):213-224, 1993.

21 This final rule provides a narrow exception to the minimum package size in response to comments about vending 음 machines that sell packaged single cigarettes.

22 Wilson, D.H., et al., 15s: They Fit in Everywhere-O Especially the School Bag: A Survey of Purchases of Packets of 15 Cigarettes by 14 and 15 Year Olds in South Australia, Supplement to Community Health Studies, vol. XI, No. 1 , pp. $16 \mathrm{~S}-20 \mathrm{~S}, 1987$

231994 SGR, op. cit., p. 249

24 Response Research, Inc., Study of Teenage Cigarette Smoking $\overline{\overline{\mathrm{c}}}$ and Purchase Behavior, for the National Automatic $\frac{5}{7}$ Merchandising Association, Chicago, p. 23, June/July $\underset{\mathbb{Q}}{1989 .}$

25 As with vending machines, FDA will allow the use of self-service displays (merchandisers) in facilities in which $\vec{O}$ retailers ensure that persons under the age of 18 are not $\vec{O}$ present at any time.

26 IOM, op. cit., p. 215, citing Roswell Park Cancer Institute. $\vec{\omega}$ Survey of Alcohol, Tobacco and Drug Use: Ninth Grade Students in Erie County, 1992. Buffalo, N.Y.: Roswell Park $\overparen{\curvearrowright}$ Cancer Institute, Department of Cancer Control and Epi- or demiology, 1993.

27 Kropp, R., A Position Paper on Reducing Tobacco Sales to Minors by Prohibiting the Sale of Tobacco Products by Means $\omega$ of Self-Service Merchandising and Requiring Only VenderAssisted Tobacco Sales, North Bay Health Resources Center, 윽 Petaluma, California, November 3, 1994.

28 IOM Report, op. cit., p. 214-215.

29 Harshbarger, Scott, Attorney General, Commonwealth of Massachusetts, comment submitted to Proposed Regulations Restriction the Sale and Distribution of Cigarettes and Smokeless Tobacco Products, Docket 95N-0253, number C29885. p. 1.

30 Reducing Health Consequences of Smoking: 25 Years of Progress, $A$ Report of the Surgeon General, DHHS, PHS, CDC, $\overrightarrow{0}$ National Center for Chronic Disease Prevention and Health Promotion (NCCDPHP), OSH, DHHS Pub. No. o 89-8411, p. 597, 1989

31 Report to Congress for 1993, Pursuant to the Federal Cigarette Labeling and Advertising Act, Federal Trade Commission Table 3 and 3D, 1995; Federal Trade Commission Report to Congress: Pursuant to the Comprehensive Smokeless Tobacco $\overline{0}$ Health Education Act of 1986, p. 25-35, 1995.

32 Fischer, P.M., et al., Brand Logo Recognition by Children Aged 3 to 6 Years, $\mathcal{F} A M A, 266(22): 3145-3148,1991$.

33 Changes in the Cigarette Brand Preferences of Adolescent Smokers-United States, 1989-1993, MMWR, CDC, 3 DHHS, 43(32):577-581, 1994.

34 Central Hudson Gas and Electric Corp., v. Public Service Commission of N.Y, 447 U.S. 557 (1980)

35 Cigarette Smoking-Attributable Mortality and Years of Potential Life Lost-United States, 1990, MMWR, CDC, 음 DHHS, vol. 42, no. 33. Pp. 645-649.

36 SGR 1994, op. cit., p. 65.

37 op. cit. footnote 6 .

38 Outdoor: It's Not a Medium, It's a Large, [sic] marketing material produced by the Outdoor Advertising Association of America, Washington, D.C.

39 BKG Youth survey, cited in Advertising Age, April 27, 1992.

40 Roper Starch Worldwide, New York, N.Y., Advertising Char- 3 acter and Slogan Survey, November, 1993, conducted for the R.J. Reynolds Tobacco Company, Study \#343-189. p. O 7 .

41 Barents Group, LLC, citing Publishers Information Bureau 음 and Mediamark Research, Inc., pp. 53-54.

42 Teen-Age Attitudes and Behavior Concerning Tobacco-Report of $D$ the Findings, The George H. Gallup International Institute, Princeton, N.J., pp. 17, 59, September 1992.

43 Slade, John. "Tobacco Product Advertising During Motor $N$ Sports Broadcasts: The Quantative Assessment." 9th World Conference on Tobacco and Health, Paris, Oct. 10-14, 1994. N

44 "Diamond Ridge Motorosports and Hanna-Barbera, Inc., N to form Wacky Racing Team Changing Face of NASCAR; Deal Launches Cartoon Network Consumer Branding Initiative," Business Wire, November 10, 1995.

45 Charlie Cooper, NASCAR properties, quoted in Children's Business, July 1994

46 Simonich, W. L., Government Antismoking Policies, Peter Lang Publishing, Inc., 1991

47 Lewit, E.M., D. Coate, and M. Grossman, "The Effects of $\bar{O}$ Government Regulation on Teenage Smoking," fournal of $\vec{D}$ Law and Economics, XXIV(3):545-573. 1981. 